\title{
Novedades florísticas en la Reserva Nacional Roblería del Cobre de Loncha: Calceolaria philippii sp. nov. (Calceolariaceae) para la flora de Chile y ampliación de la distribución de Anemone rigida Gay (Ranunculaceae)
}

\section{Floristic news at the Roblería del Cobre de Loncha National Reserve: Calceolaria philippii sp. nov. (Calceolariaceae) a new species for the Chilean flora and expansion of distribution of Anemone rigida Gay (Ranunculaceae)}

\author{
María Teresa Eyzaguirre Philippi \\ Fundación R.A. Philippi de Estudios Naturales, Corte de Apelaciones 1051, Depto. 403, Vitacura, Santiago, Chile. \\ mteyzaguirre@fundacionphilippi.cl
}

\begin{abstract}
Calceolaria philippii Eyz. (Calceolariaceae) is described as a new species. The distribution of Anemone rigida Gay (Ranunculaceae) is extended and a new description is added. Both grow at Reserva Nacional Roblería del Cobre de Loncha on the Coastal range of central Chile.
\end{abstract}

La Reserva Nacional Roblería del Cobre de Loncha se encuentra en la Región Metropolitana, provincia de Melipilla, comuna de Alhué. Forma parte del Sistema Nacional de Áreas Silvestres Protegidas del Estado (SNASPE) y es administrada por CONAF de Doñihue, Región de O’Higgins. Fue creada en julio de 1996 y tiene una superficie de 5.870 hectáreas. Comprende el cordón de cerros que cierra por el sureste la cuenca del estero Carén donde se ubica el tranque de relaves de la mina de cobre El Teniente de Codelco. La vegetación del lugar (Gajardo 1994) se incluye en la subregión del bosque esclerófilo, con diferentes componentes según la orientación de la ladera. En los sectores altos es reemplazado por el bosque caducifolio de Santiago, cuya especie dominante es Nothofagus macrocarpa (A. DC.) F.M. Vásquez \& R. Rodr. acompañado de especies como Citronella mucronata (Ruiz \& Pav.) D. Don y Beilschmiedia berteroana (Gay) Kosterm.

En junio de 2007 se visitó por primera vez la reserva. Entre la hojarasca del bosque caducifolio se encontró hojas que podrían corresponder a Anemone rigida Gay. Para comprobarlo, se llevaron a cabo nuevas visitas en la primavera de 2012 y 2013, encontrando una población de dicha especie en plena floración junto a una Calceolaria desconocida.

Calceolaria philippii Eyz. sp. nov.

TIPO: Chile. Región Metropolitana. Provincia de Maipo, Reserva Nacional Roblería del Cobre de Loncha. Alto de la Cebolla, $1.300 \mathrm{~m}\left(34^{\circ} 10^{\prime} \mathrm{S} 70^{\circ} 58^{\prime} \mathrm{W}\right) \mathrm{M}$. Teresa Eyzaguirre, 8-XI-2012 (SGO 163587).
Rosette leaves, ovate, very short petiole, almost entire margin, rough, inflorescence up to twelve flowers, yellow gold, hairy calyx, flowers with an open crenate lower lip with the middle crenel protruding.

Planta perenne de 34 a $68 \mathrm{~cm}$ de alto. Hojas basales en roseta, aovadas y lanceoladas de 6 a 9,5 cm de largo por 2,5 a 4,5 cm de ancho, con pecíolo muy corto o casi sésil y de forma muy constante entre los diferentes individuos. Margen levemente crenado, o casi entero y ápice truncado; ásperas, con ambas caras cubiertas de pelos rectos, finos y otros más anchos de color blanco; envés más claro que la haz. Tallo de color oscuro hacia la mitad inferior con el mismo tipo de pelos, con uno o dos nudos provistos de hojas pequeñas, lanceoladas y con dos lóbulos en la base (Fig. 1 A). Inflorescencia, una cima con 7-12 flores (Fig. 1 B). Cáliz piloso; corola de color amarillo oro, con labio superior más corto que el cáliz y el ápice agudo; labio inferior de $20 \times 16$ × $10 \mathrm{~mm}, 5$ veces más largo que el superior, muy inflado, angostándose hacia la base, abierto, con puntos de color purpúreos por arriba y estrías en el interior; colgante, curvándose hacia arriba, de forma semicircular visto de lado, con 5 almenas en la parte media superior, la central más larga que las demás. Androceo con estambres un poco mayores que el labio superior, las anteras del mismo largo y perpendiculares a estos, polen blanquecino. Fruto desconocido.

Calceolaria philippii Eyz. se parece a Calceolaria corymbosa Ruiz \& Pav. en el hábito y apariencia de la flor. Se diferencia de ésta por la mayor longitud del pedúnculo, 
el mayor tamaño de la flor y por la forma del labio inferior, semicircular visto de lado y con el borde crenado curvado hacia arriba con el diente central notoriamente sobresaliente (Fig. 1 C).

Material estudiado: Región Metropolitana, Provincia de Maipo, Reserva Nacional Roblería del Cobre de Loncha. Alto de la Cebolla, 1.300 m s.n.m., 18-XI-2013 (SGO 163588).

ETIMOLOGÍA

Esta nueva especie se la dedico a mi tatarabuelo Rodulfo Amando Philippi en agradecimiento al invaluable aporte al conocimiento de nuestra biodiversidad.
DisTRIBUCIÓN Y ECOLOGÍA

La especie, hasta ahora, es endémica de la Región Metropolitana donde crece cerca de su límite sur. Vive entre la hojarasca de un bosque de Nothofagus macrocarpa (A. DC.) F.M. Vásquez \& R. Rodr. en condiciones de semisombra. Como acompañantes se encuentran: Calceolaria corymbosa ssp. corymbosa Ruiz \& Pav., Anemone rigida Gay, Olsynium scirpoideum (Poepp.) Goldblatt, Tropaeolum tricolor Sweet, Adiantum gertrudis Espinosa, Alstroemeria revoluta Ruiz \& Pav., Retanilla ephedra (Vent.) Brongn., Ribes punctatum Ruiz \& Pav., Vicia nigricans Hook. \& Arn. Es una población de muchos individuos, pero ocupa un área restringida en una ladera de exposición sur. Florece en noviembre.
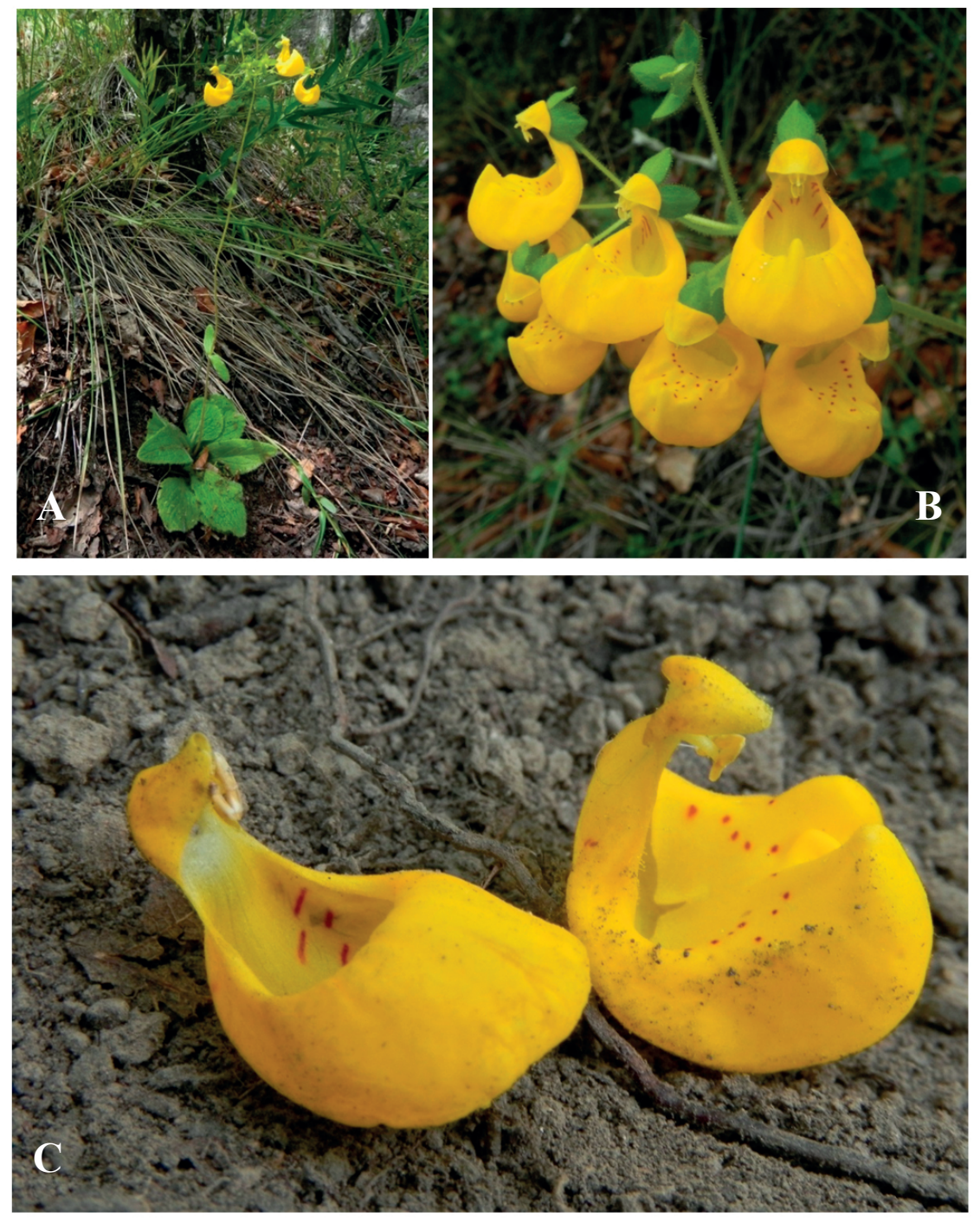

Figura 1. A. Hábito de Calceolaria philippii, B. Flores, C. Flor de Calceolaria corymbosa ssp. corymbosa y flor de Calceolaria philippii (Fotografías de M.T. Eyzaguirre).

FIGURE 1. A. Habit of Calceolaria philippii, B. Flowers, C. Calceolaria corymbosa ssp. corymbosa and Calceolaria philippii flowers (Photographs by M. T. Eyzaguirre). 


\section{ANEMONE RIGIDA Gay}

C. Gay, Fl. Chil. 1: 25. 1845. "Esta especie se cria en los prados de las cordilleras de Talcaregue (provincia de Colchagua), á una altura de 6800 p.;...”

\section{DESCRIPCIÓN}

Hierba perenne de hasta $40 \mathrm{~cm}$ de alto cuya parte aérea desaparece en invierno, provista de un rizoma grueso y leñoso (Fig. $2 \mathrm{C}$ ) con la base de las hojas antiguas adheridas. Pecíolos largos de hasta $18 \mathrm{~cm}$, estriados, blanquecinos, pubescentes y con la base envainadora. Hojas con la lámina suborbicular o reniforme de 5-13 x 7-16,5 cm, tripartida, con segmentos obovados, bilobulados y de margen dentado.
Escapos muy largos con cimas de varias flores (Fig. 2 A). Involucro trífido con segmentos sésiles 2 a 3 partidos. Perigonio petaloide, con 5 a 8 tépalos de color rosado intenso (Fig. 2 B). Estambres 30 a 50 con los filamentos más anchos en la base. Carpelos 40 a 70 cilíndricos, asimétricos con un estilo grueso, curvo y papiloso. Aquenios glabros, semiovoides.

Habitualmente citada como subarbusto (planta semejante a un arbusto, generalmente pequeña y sólo lignificada en la base, Font Quer 1993), entre otros por Ruiz (2001), probablemente debido a que, en las muestras de herbario, sus rizomas leñosos podrían confundirse con tallos aéreos.
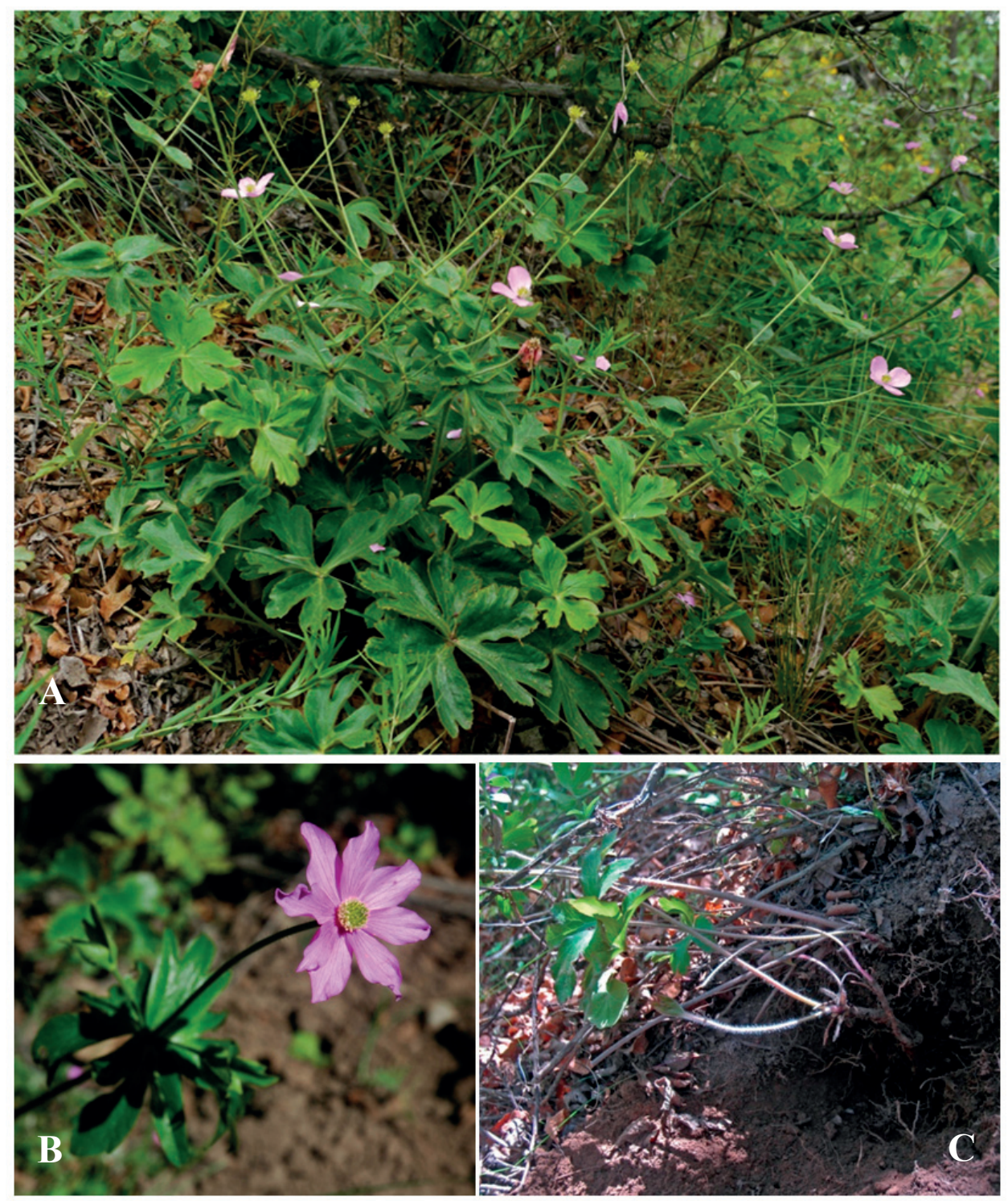

Figura 2. A. Hábito de Anemone rigida, B. Flor, C. Hojas y rizoma. (Fotografías de M. Teresa Eyzaguirre).

Figure 2. A. Habit of Anemone rigida, B. Flower, C. Leaves and rizome (Photographs by M. Teresa Eyzaguirre). 
DiSTRIBUCIÓN Y ECOLOGÍA

Especie endémica de Chile. Tiene un hábitat restringido al sotobosque bajo Nothofagus entre los 1.000 y $1.500 \mathrm{~m}$ s.n.m. Descrita por Claudio Gay en 1845, en los prados de las cordilleras de Talcaregue (Colchagua) y coleccionada hasta ahora, desde la Región de O’Higgins a la del Maule (provincia de Curicó) sólo en la precordillera de Los Andes. Este registro amplía su distribución hacia oeste en la cordillera de la Costa.

MATERIAL ESTUdiAdo

Región Metropolitana, Provincia de Maipo, Reserva Nacional Roblería del Cobre de Loncha. Alto de la Cebolla, $1.300 \mathrm{~m}$ (3410'S 7057'W), 8-IX-2012, M. Teresa Eyzaguirre (SGO 163589). Región de O’Higgins, Colchagua, 1860, L. Landbeck (SGO 063231). Región del Maule, Curicó, Potrero Grande, 1-XI-1957, Wolf Maige (SGO 072163). Los Queñes, I-1933, C. Grandjot (SGO 117207), Sureste Los Queñes, 16-XII-1973, G. L. Stebbins 8997 (SGO 140031).

\section{AGRADECIMIENTOS}

A Mélica Muñoz por revisar mi manuscrito y por su constante apoyo a mis ganas de aprender. A mis amigos Hernán Hevia y Cristina Lepeley por acompañarme a terreno con gran entusiasmo, a pesar de las dificultades del camino.

\section{BIBLIOGRAFÍA}

Ehrhart, C. 2000. Die Gattung Calceolaria (Scrophulariaceae) in Chile. Bibliotheca Botanica Heft 153. Stuttgart. 283 pp.

Font Quer, P. 1993. Diccionario de Botánica. Tomos I y II. Editorial Labor, Barcelona. España, 1244 pp.

Gajardo, R. 1994. La Vegetación Natural de Chile. Editorial Universitaria. Santiago de Chile. 165 pp.

GAY, C. 1845. Ranunculáceas. Historia física y política de Chile, Botánica 1: 25.

RuIz, E. 2001. Ranunculaceae. En: C. Marticorena \& R. Rodríguez (eds.), Flora de Chile 2(1): 40-47.

Recibido: 04.12.13

Aceptado: 05.05.14 